\title{
PODONOMUS FASTIGIANS BRUNDIN 1966 (CHIRONOMIDAE: PODONOMINAE): REDESCRIPTION OF THE ADULT MALE AND FEMALE, THE PUPA, AND DESCRIPTION OF THE LARVA ${ }^{1}$
}

\author{
Augusto Siri, ${ }^{2}$ Analía Paggi, ${ }^{2}$ and Mariano Donato ${ }^{3}$
}

ABSTRACT: The larva of Podonomus fastigians is described for the first time, and the male and female adult and pupa are redescribed and illustrated. This is the first report of the non-biting midge $P$. fastigians in Argentina. Ecological remarks are included.

KEY WORDS: Argentina, Podonomus fastigians, redescription, Podonominae, new record

The subfamily Podonominae (Diptera: Chironomidae) includes species that inhabit cold streams and brooks. An unexpected record was Parochlus bassianus Brundin, whose larvae, pupae and pharate adults were founded in the phytotelmic plant Richea pandanifolia (Cranston and Kitching, 1995). This subfamily shows a marked concentration of the species distributed in the southern hemisphere, mainly in South America. The knowledge for this region is based principally on the monograph of Brundin (1966), who described 98 species from South America and 21 species from Argentina.

The genus Podonomus Philippi includes 34 valid species distributed in five groups. It is so far known only from the southern hemisphere, occurring from the higher parts of the Bolivian Andes to the Magellanic peninsula (Brundin, 1966). Following the biogeographical schemes proposed by Cabrera and Willink (1973), this genus is distributed in the Andean-Patagonian domain of the Neotropical region and Subantarctic domain of the Antarctic region. However, note that $P$. pepinellii was recently described from the Atlantic Rainforest, Amazonian domain, recorded at $1853 \mathrm{~m}$ asl, in an area with a cloud forest vegetation (Roque and Trivhinho-Strixino, 2004).

The nudipennis-group consists of four species: $P$. nudipennis Edwards, P. fastigians Brundin, P. apolobombae Brundin and P. acutus Wirth. The first three species were described from the male, female and pupa, the last only as the adult male. Brundin's (1966) description of the nudipennis group was based mainly on the description of P. nudipennis. Brundin (1966) recorded P. fastigians from the High Andes of Bolivia and Peru. The male and pupa of this species strongly resemble $P$. nudipennis from southern Chile and Argentina.

\footnotetext{
${ }^{1}$ Received September 17, 2008. Accepted on November 9, 2008.

${ }^{2}$ ILPLA (Instituto de Limnología "Dr. Raúl A. Ringuelet") CONICET (Consejo Nacional de Investigaciones Científicas y Técnicas) - La Plata / UNLP (Universidad Nacional de La Plata). CC712 (1900), La Plata, Argentina. E-mails: augusto@ilpla.edu.ar and anpaggi@ilpla.edu.ar, respectively.

${ }^{3}$ Laboratorio de Sistemática y Biología Evolutiva (LASBE), Museo de La Plata, Paseo del Bosque s/n (1900), La Plata, Argentina. E-mail: mdonato@fcnym.unlp.edu.ar
} 
New material collected allows us to describe the larva of $P$. fastigians for the first time, and to redescribe the morphology of the adult male and female, and the pupa of this species.

\section{METHODS}

Larvae and pupae were collected using a drift net, while adult males were collected with a sweep net. Material was fixed in 70\% ethanol and transported to the laboratory, where specimens were mounted in Canada balsam. Collected larvae were all prepupae, allowing a secure association with the pupal stage, and the female description was based on pharate pupae, which did not allow us to describe structures such as the wing, leg segment lengths and their proportions, and the plume of the antennae. General terminology of descriptions follows Sæther (1980); pupal thoracic setal terminology follows Cranston and Edwards (1998). Measurements are in $\mu \mathrm{m}$ unless otherwise stated. The measurements are given as ranges followed by a mean when four or more measurements are made, followed by the number measured in parentheses (n).

The material is deposited in the collection of Museo de La Plata (MLP, Argentina).

\section{SYSTEMATIC ENTOMOLOGY Podonomus fastigians Brundin 1966}

Material Examined: ARGENTINA: 12 males, 3 pharate females, 15 pupae, 12 larvae. Little stream afluent on Socompa lagoon, 24 $31^{\prime} 20.7^{\prime \prime S}, 68^{\circ} 11^{\prime}$ 58.9"W, 3577 m asl, Salta province, 11-I-05, leg. M. Donato (MLP).

Diagnosis: A group of stout setae on the dorsomedian surface of the gonocoxite of $P$. fastigians clearly distinguishes the adult males of this species from the other species of the nudipennis group. The adult males of $P$. fastigians resemble those of $P$. nudipennis but are distinguished from the latter by the wider basal region of the gonocoxite and its inner S-curved margin, the straight and stouter subapical lobe of the gonostylus, and by the shorter megaseta of the apical lobe. The adult female of $P$. fastigians can be distinguished from the remaining species of the nudipennis-group by the widened distad and rounded apically cercus, containing five strong subapical setae (three dorsal and two ventral; the anterior setae shorter than the others in both groups).

The pupa of $P$. fastigians also strongly resembles that of $P$. nudipennis. The porous plate of the thoracic horn of both species has a similar arrangement of the pores, but the area with close-set pores is broader in the former. Moreover, a transverse ridge with irregularly placed small denticles present posteriorly on segments III-VIII also characterized $P$. fastigians.

\section{Redescription of the adult male and female}

Male imago $(n=8-12$, except when otherwise stated) (Figs. 1-5). Total length 2.25-2.88, $2.63 \mathrm{~mm}$, wing length 1.87-2.28, $2.12 \mathrm{~mm}$; width $0.60-0.68,0.63 \mathrm{~mm}$. 
Total length/wing length 1.20-1.35, 1.28. Wing length/length of profemur 1.201.35, 1.28. Coloration deep black.

Head (Fig. 2). AR (flagellomeres 13 plus 14 divided by the length of the remaining flagellomeres): 0.45-0.57 (2). Antenna with 14 flagellomeres (Fig. 1). Ultimate flagellomere 99-110 (2); penultimate flagellomere 175-234 (2). Temporal setae: 4-5 outer verticals; 5-7 inner verticals, 1-3 frontals, 1-2 postorbitals. Clypeus with 3-6, 4 setae. Tentorium 122-162, 141 long. Palpomere lengths: 31-41, 32; 41-63, 52, 91-124, 108, 75-91, 84, 100-112, 105.

Thorax (Fig. 4). Antepronotum with 2-4, 3 lateral setae, dorsocentrals 21-31, 26; prescutellars 4; acrostichals 14-26, 20; prealars 10-18, 14, biserial; supraalars 1-2, 1. Scutellum with 2-4, 4 setae. Preepisternals absent.

Wing (Fig. 3). Membrane bare, with microtrichia.VR 0.90-1.00, 0.95. C extension 132-201, 169 long. Brachiolum with 4-6, 5 setae; R with 10-14, 12; R1 with 2-3; R4+5 S-shaped and with 2-4, 3 setae. Squama with 3-5, 4 setae.

Legs. Spur of front tibia 47-59, 51 long; spurs of middle tibia subequal: $35-$ 45, 40 and 33-41, 34 long; of hind tibia: 73-102, 83 and 26-43, 36 long. Comb with 13-17, 16 setae. Lengths and proportions of legs in Table 1. Coxae with 56,6 setae in a single oblique row (7).

TABLE 1. Lengths $(\mu \mathrm{m})$ and proportions of male legs Podonomus fastigians. Abbreviations: Femur (fe); Tibia (ti); Tarsomeres 1-5 ( $\left.\operatorname{ta}_{1-5}\right)$; Leg Ratio (LR), ratio of metatarsus divided by tibia; "Beinverhältnisse" (BV), combined length of femur, tibia, and basitarsus divided by combined length of tarsomeres 2-5; "Schenkel-Scheine-verhältnis" (SV), femur plus tibia divided by metatarsus.

\begin{tabular}{lcccrr}
\hline & Fe & ti & ta $_{1}$ & \multicolumn{1}{c}{ ta $_{2}$} & \multicolumn{1}{c}{ ta $_{3}$} \\
\hline $\mathrm{p}_{1}$ & $558-747,686$ & $598-739,675$ & $380-390,349$ & $182-236,210$ & $108-126,117$ \\
$\mathrm{p}_{2}$ & $639-805,748$ & $606-730,681$ & $291-332,317$ & $163-216,192$ & $91-118,104$ \\
$\mathrm{p}_{3}$ & $755-961,852$ & $797-951,895$ & $415-515,472$ & $282-349,325$ & $128-152,140$ \\
\hline
\end{tabular}

\begin{tabular}{cccccc}
\hline & $\mathrm{ta}_{4}$ & $\mathrm{ta}_{5}$ & $\mathrm{LR}$ & $\mathrm{BV}$ & $\mathrm{SV}$ \\
\hline $\mathrm{p}_{1}$ & $61-77,71$ & $59-77,68$ & $0.45-0.54,0.52$ & $3.41-4.06,3.71$ & $3.69-4.38,3.86$ \\
$\mathrm{p}_{2}$ & $55-73,65$ & $55-73,67$ & $0.44-0.48,0.46$ & $3.72-4.42,4.15$ & $4.29-4.74,4.55$ \\
$\mathrm{p}_{3}$ & $59-77,69$ & $57-7568$ & $0.51-0.59,0.54$ & $3.52-3.85,3.67$ & $3.44-3.84,3.68$ \\
\hline
\end{tabular}




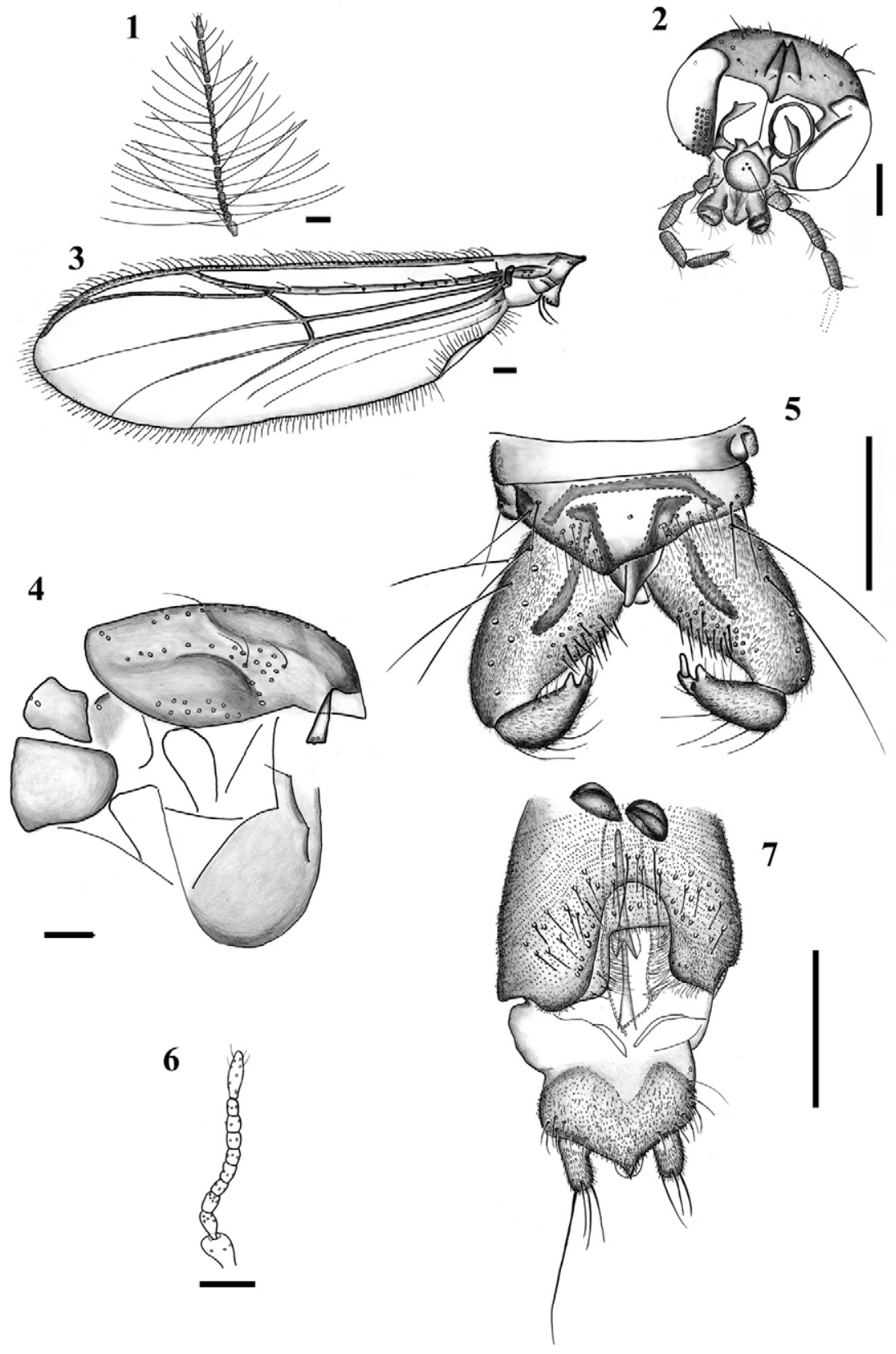

Figures 1-7. Podonomus fastigians Brundin imagines. Male (1-5): 1. Antenna. 2. Head, frontal view. 3. Wing. 4. Thorax, lateral view. 5. Hypopygium, dorsal view. Female (6-7): 6. Antenna. 7. Genitalia, ventral view. Scale bars $=100 \mu \mathrm{m}$. 
Hypopygium (Fig. 5). Anal point lacking. Setae on tergite IX 18-24, 21 (7), laterosternite IX with 3-5, 4 setae (7). Phallapodeme 81-102, 90 long; transverse sternapodeme 57-91, 76 long, straight. Virga absent. Gonocoxite 122-162, 136 long; with a conspicuous group of 19-31, 23 stout setae on the dorsomedial surface of the inner margin. Gonostylus 69-83, 76 long; megaseta 16-24, 20 long; subapical lobe spine shaped 6-12, 11 long. HR 1.51-1.95, 1.80; HV 0.33-38, 0.35 . The $x$ and $y$ setae discernible, but a conspicuous $p$ seta not developed.

Female imago $(n=3$, except when otherwise stated) (Figs. 6-7). Total length 2.40-2.72 mm (2).

Head. Antenna with 9 flagellomeres (Fig. 6), AR (flagellomere 9 divided by remaining): $0.24-0.27$. Lengths of flagellomeres: $35-37 ; 28-31 ; 24 ; 24 ; 24 ; 24$; 24-28; 24-28; 65-81. Temporal setae 13-15 (2). Clypeus with 3 setae (1). Palpomere lengths: $26 ; 41 ; 55 ; 53 ; 67$ (1).

Thorax. Antepronotum with 3 setae (2). Dorsocentrals 19 (1); acrostichals 19-22 (2); prealars 13-16 (2); supraalars 1-2 (2). Scutellum with 6 setae (2). Preepisternals absent.

Legs. Spur of front tibia 33-41 long (2); spurs of middle tibia: 28-31 and 24 long (2); of hind tibia: 55-71 long. Comb with 15-16 setae.

Genitalia (Fig. 7). Cercus 45-51 long. Seminal capsule 28-40; notum 82 long, ramus 56 long (1); sternite VIII with 55 setae (1), sternite IX without central setae and with 2-4 lateral setae; sternite $\mathrm{X}$ well developed, with an acute posterior projection, with 16-18 setae distributed in two posterolateral groups. Tergite IX with 16-22 posterior setae. Gonapophysis VIII with 4 setae. Postgenital plate 45-53 long.

\section{Redescription of the pupa}

Pupa (n=8-15, except when otherwise stated) (Figs. 8-12). Total length 0.660.74, $0.70 \mathrm{~mm}$. Frontal apotome as in Fig. 8, frontal setae 31-41, 44 long (7).

Cephalothorax (Fig. 10). Frontal apotome as in Fig. 8. Thorax rugose dorsally. Chaetotaxy: median antepronotals 2, 37-58, 46 and 34-51, 41 long (7); lateral antepronotals 2, 37-55, 43 and 12-16, 14 long, the shorter spine shaped; precorneals 2, 14-44, 29 long in addition to a short (7-11, 8 long) and very thin seta located at half distance between precorneals and the medial antepronotals; located at 43-71, 50 from precorneals, and at 31-51, 41 to medial antepronotal; dorsocentrals in cluster of 3 , plus $1\left(\mathrm{Dc}_{4}\right.$ ?) and a scar close to supraalar position. Distance between $\mathrm{Dc}_{1}$ and $\mathrm{Dc}_{2}$ 12-26, 16; between $\mathrm{Dc}_{2}$ and $\mathrm{Dc}_{3}$ 14-37, 23; between $\mathrm{Dc}_{3}$ and $\mathrm{Dc}_{4}$ ? 134-166, 145; $\mathrm{Dc}_{4}$ ? and scar 8-14, 12. Metanotals 2 (5). Thoracic horn 317-401, 360 long; 100-142, 121 width, broader at apex; with a very large porous plate and reduced stalk (51-71, 57 long). Surface of porous plate with compact pore groups, each consisting of close set pores appearing as a unit (as in Fig. 9).

Abdomen (Figs. 11-12). Ventral lamella present. Segments III-VIII with lateral processes, processes of segment VIII shorter than the others. Chaetotaxy: 
segments II-VII with 4 lateral setae, one located in the lateral process and the other 3 setae situated anteriorly; segment VIII with 6-8 lateral wavy setae; seg-
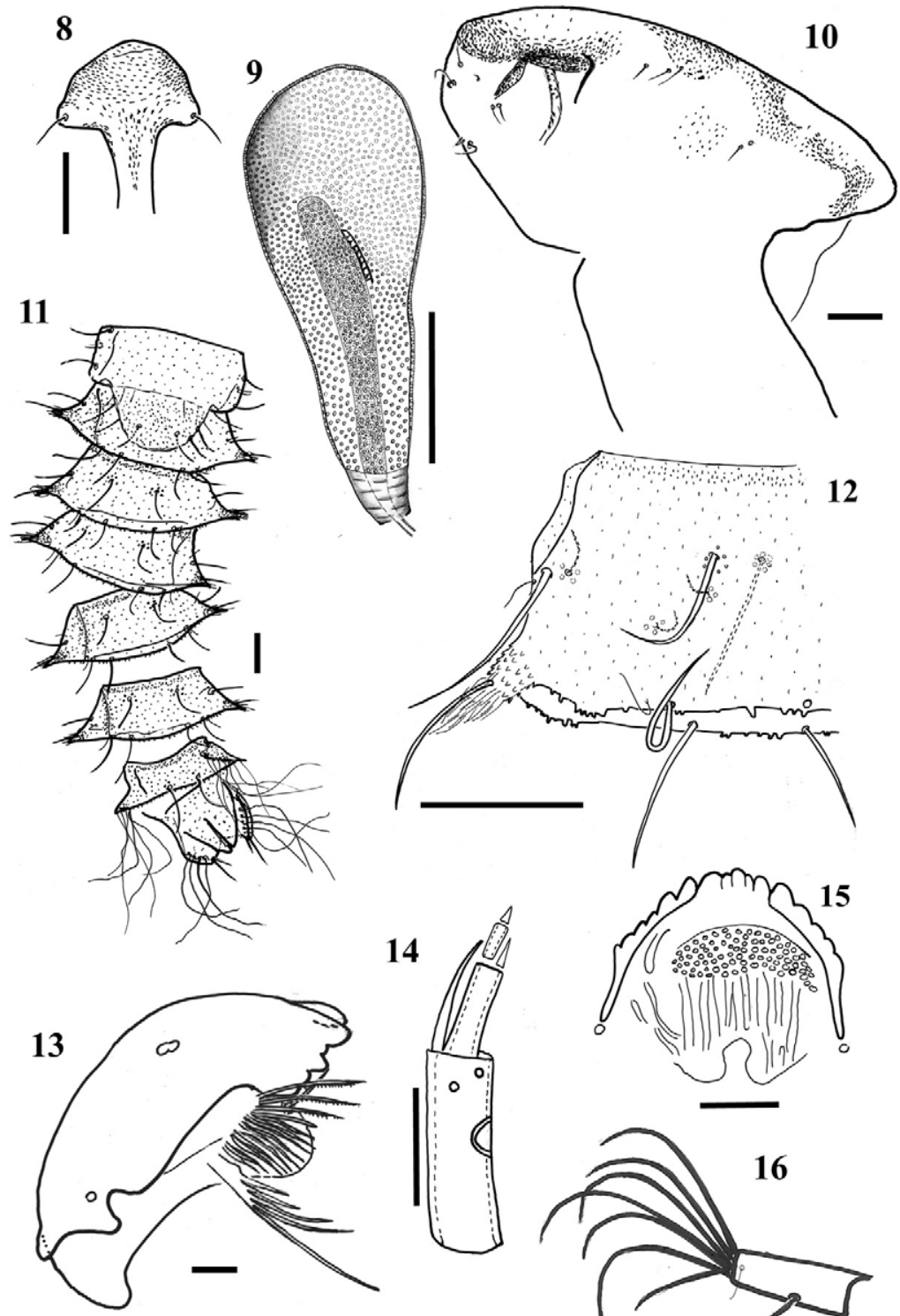

12

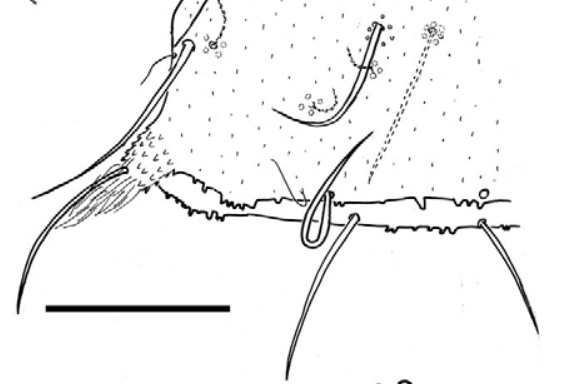

14
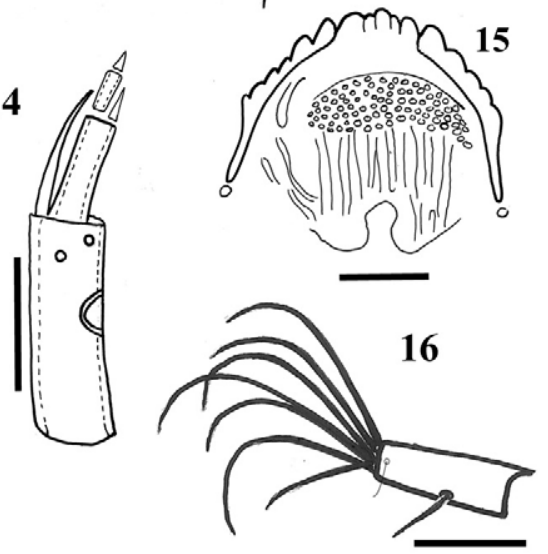

Figures 8-16. Podonomus fastigians Brundin immatures. Pupa (8-12): 8. Frontal apotome. 9. Thoracic horn. 10. Cephalothorax, lateral view. 11. Abdomen, ventral view (segment I missing). 12. Detail of abdominal segment IV (ventral). Larva (13-16): 13. Mandible. 14. Antenna. 15. Mentum. 16. Procercus. Scale bars: 8-12,16 $=100 \mu \mathrm{m} ; 13-15=20 \mu \mathrm{m}$. 
ment IX with lateral 7-9 wavy setae, and 2 anal macrosetae 67-112, 88 and 4785, 66 long. Dorsally on tergites II-VII, a pair of three dorsomedial setae arranged in oblique rows, each of them surrounded by small tubercles; the most anterior pair of these setae are stouter while the other two pairs are shorter and thinner; a pair of three posterior dorsal setae on these segments, being the most outer seta larger than inners. Segment VIII without dorsomedial setae, and with only one pair of posterior dorsal setae. Segment II with 0 ventral setae, segments III-VII with one pair of ventromedial setae and a pair of three posterior ventral setae (the most outer setae very thin and short). Segment VIII without ventromedial setae, and with only one posteroventral pair. Anal lobe length 193-242, 222; with two terminal setae. Genital sac length 102-122, 112.

\section{Description of the fourth larval instar}

Larva ( $\mathrm{n}=8-12$, except when otherwise stated) (Figs. 13-16). Total length 2.9-3.2, $3.1 \mathrm{~mm}$ (5). Head capsule dark brown, 293-386, 352 long. Head obscured with a shallow area on each ventromedial side; abdominal and thoracic segments with long setae (75-89, 85 long).

Lengths of antennal segments: 41-49, 44; 16-20, 20; 5-7, 7; 4. AR 1.3-1.6, 1.5. Basal antennal segment 14-18, 17 wide; distance from base to ring organ 2428, 27; to basal setae marks 32-44, 39 and 28-43, 36 respectively; blade on second antennal segment 20-25, 22 long; stylus 4 long (Fig. 14). Labral setae I simple. Mandible (Fig. 13): 93-101, 97 long; preapical, apical and four inner teeth; seta subdentalis 13-16, 14 long (7), inserted on inner surface of mola, straight and reaching the second inner tooth. Seta interna complex, inserted on inner surface, consisting of 18-23, 20 stout branches: 14-17 shortest branches 23 long, the first three serrated on posterior margins; the posterior five longest, 45-55, 52 long, fused together before insertion (as figure 13). Mentum 81-95, 85 width; with five central irregular teeth and six pairs of lateral teeth as figure 15 . Postmentum 152-187, 173 long.

Abdomen: Procerci (Fig. 16) 112-142, 130 long; with seven apical setae 203250, 226 long (4) and two subapical setae: one 51-67, 60 long, at 51-67, 60 from base of procerci; the other 30-40, 36 long (7), thinner than the former; almost apical, situated at 7-10, 8 from the apex of procerci.

\section{Ecology and Distribution}

Podonomus fastigians was collected from the northwestern Argentina, in the Puna biogeographic province (Cabrera and Willink 1973). This province coincides with the same biogeographic province of the previous report for this species (Brundin 1966, Spies and Reiss 1996). The Puna is a plateau located in the higher Andes between 3200-4400 m above sea level from Peru and Bolivia to the north, down to northwestern Argentina and Chile.

Material was collected from a little stream about $1 \mathrm{~km}$ long, which arises from a spring and drains to Socompa saltwater lagoon. 


\section{DISCUSSION}

The presence of $P$. fastigians represents the first report of this species from Argentina, representing the most austral report of the world, as well as the first larva of the nudipennis-group to be described.

The relation between ultimate and penultimate antennal flagellomeres, and more setae on squama could be considered as additional differences between $P$. fastigians and $P$. nudipennis. The wing length of the male specimens studied in the present study does not agree with the original measurements of Brundin.

Brundin used the shape of the cercus and the number of its larger setae to differentiate $P$. fastigians adult female from $P$. apolobombae. As mentioned above, the female of the former has cerci with five large setae while P. apolobombae has only four. However, the number of large setae (4) observed in our material fits with the description of $P$. apolobombae. Since all females were pharate, we could associate the pupal exuviae with the female adults, and we consider these females as belonging to $P$. fastigians. Additional females will be necessary to demonstrate whether this character may be used to differentiate the females of $P$. fastigians and $P$. apolobombae.

In addition to the differences cited by Brundin, the pupae of $P$. fastigians are differentiated from the rest of the species group by the higher mean number of wavy setae on segments VIII and IX. Moreover, P. fastigians can be distinguished from $P$. nudipennis by the presence of rounded knobs at base of the anterior dorsal and lateral setae of the abdominal segments III-VII, and by a clearly longer and stouter seta located on each base of the lateral process.

\section{ACKNOWLEDGMENTS}

This paper was partially supported by PIP 5334 (CONICET). The authors wish to thank the two anonymous reviewers for valuable comments on the manuscript, and the third author acknowledges National Geographic Society (Grant 7646-04) for financial support. It is a Scientific Contribution $\mathrm{N}^{\mathrm{o}}$ 831 of the Institute of Limnology "Dr. R.A. Ringuelet" (ILPLA, CCT-La Plata, CONICET, UNLP).

\section{LITERATURE CITED}

Brundin, L. 1966. Transantarctic relationships and their significance, as evidenced by chironomid midges. With a monograph of the subfamilies Podonominae and Aphroteniinae and the Austral Heptagyiae. Kunglika Svenska Vetenskapakadamiens Handlingar 11(1): 1-474.

Cabrera, A. and A. Willink. 1973. Biogeografía de América Latina. Monografía No. 13, Serie de Biología, Organización de Estados Americanos, Washington, D.C., 120 pp.

Cranston, P. S. and R. Kitching. 1995. The Chironomidae of Austro-Oriental Phytotelmata (plantheld waters): Richea pandanifolia Hook. F. pp. 225-232. In, Cranston P. S. (Editor). Chironomids: from Genes to Ecosystems. Commonwealth Scientific and Industrial Research Organisation (CSIRO), Melbourne, Australia. 482 pp.

Cranston, P. S. and H. D. Edwards. 1998. Afrochlus Freeman: an African gondwanan midge and the phylogeny of the Podonominae (Diptera: Chironomidae). Systematic Entomology 23: 77-90.

Roque, F. O. and S. Trivhinho-Strixino. 2004. Podonomus pepinellii n. sp., first record of the genus and subfamily from Brazil (Diptera: Chironomidae: Podonominae). Zootaxa 689: 1-7.

Sæther, O. A. 1980. Glossary of chironomid morphology terminology (Diptera: Chironomidae). Entomologica Scandinavica Supplement 14: 1-51.

Spies, M. and F. Reiss. 1996. Catalog and bibliography of Neotropical and Mexican Chironomidae (Insecta, Diptera). Spixiana Supplement 22: 61-119. 